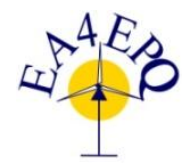

International Conference on Renewable Energies and Power Quality (ICREPQ'14)

Cordoba (Spain), $8^{\text {th }}$ to $10^{\text {th }}$ April, 2014

Renewable Energy and Power Quality Gournal (RE\&PQJ)

ISSN 2172-038 X, No.12, April 2014

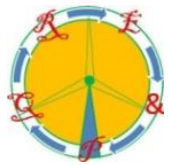

\title{
APPLICATION OF DIFFERENT INDICES OF PERFORMANCE EVALUATION OF FORECAST FOR WIND SPEEDS
}

\author{
J. C.P. Dominguez ${ }^{1}$, F. D. L. Silva ${ }^{2}$ and P. C. M. Carvalho ${ }^{2}$ \\ ${ }^{1}$ Escuela Técnica Superior de Ingenieros (ETSI) \\ Universidad de Sevilla \\ Sevilla ( España) \\ ${ }^{2}$ Department of Electrical Engineering \\ Federal University of Ceará \\ Fortaleza (Brasil) \\ Phone:+55 85 33669585, e-mail: jcar6@hotmail.com, fdanielce@yahoo.com.br, carvalho@dee.ufc.br
}

Summary. In this study, firstly, we'll see an introduction about wind energy and its current use in Brazil, giving an overview of the development of the treatment of wind forecasting through two techniques for forecasting. One of the data sources available are predictions from numerical models, due to the large volume of information, it were saved only prediction's images made. Worked these images you can retrieve a value of wind speed forecast for a specific city.

We'll show the used methodology, seeing how processed data were taken, we'll also see the accumulator's installations, which will contain for the same date, actual values and projected wind speeds, and we'll conclude with the indexes' calculations for evaluating performance working with three indexes: "MAPE", "RMSE", "MAE", in the range of a year in four quarters and 45 samples in each quarter. Then we'll see according to several articles, the most used indexes evaluation, which are "MAPE", "RMSE" and "MAE", that's the reason in this study we're also going to work with these ones. Finally, we'll proceed to the analysis of the results. In the rainy season and the dry season, we will see what was the numerical model that best approached to the reality.

Key words forecast, performance evaluation, prediction error, numerical weather prediction model.

\section{Introduction}

The world capacity for generating electricity through wind power has been increasing year by year. To get an idea of the magnitude of the expansion of wind energy in the world. In 2010 was approximately $153.1 \mathrm{GW}$, in 2011 was $175.48 \mathrm{GW}$, in 2012, $198.39 \mathrm{GW}$, and in 2013 is estimated to reach this magnitude of $222.79 \mathrm{GW}$. [1]

The production capacity of wind power in Brazil has been increasing year by year also. In 2008 was $341 \mathrm{MW}$, in 2010 was $920 \mathrm{MW}$ spent in 2012 amounted to $1200 \mathrm{MW}$. [2]. To take full advantage of this generating capacity of wind power, a good prediction of the wind speed is required. These wind forecasts are realized by mathematical models of the climate. Begins with some initial conditions measured by satellites and thousands of stations and weather balloons located around the world.
The quality of these measures is essential for a correct prediction of forecasts. The mathematical formulation of the model of evolution of the atmosphere is based on a partial differentials equations, which due to its huge size doesn't have an analytical solution system. That's why we need to use numerical tools to solve the system.

There's a lot of numerical models that have been developed by various agencies and organizations meteorological. In this study, we'll pay attention in specifics numerical models: NWP (Numerical Weather Prediction), with two forecasting techniques: Regional Atmospheric Modeling System (RAMS) and Weather Research and Forecasting (WRF). With the speeds' wind's predictions of these two techniques, we evaluate which moved closer to reality by applying of several indices of performance evaluation of forecasts

\section{OBJETIVES}

Evaluate the performance of forecasts of wind speed according to different evaluation criteria

Specifics objectives.

- Development of indexes of performance analysis of forecasts of wind speed

- Compare the performance of different configurations of the methods in different seasons, to the town of Catarina city in the state of Ceará Brazil, for the year 2010/2011

- Quantify the use of indexes of performance analysis forecasts of wind speed.

- Apply different indexes of performance for analyzing the predictions of RAMS and WRF models simulated by FUNCEME to the same city 2010/2011.

\section{State of art}

\subsection{Wind forecast}

The wind forecast can also be defined as an estimate of future values of wind speed and direction at different heights with an estimation of the error in its output. The 
research in the area of wind forecasting began in the 1980s. Thereafter numerous research centers have invested in developing methods and tools that have generated a wide variety of forecasting models. Some of them are commercial, and offer their services to companies operating wind resources.

\subsection{Forecasting techniques}

There are three types of forecasting techniques constrained by the available data:

- "Delphi Method": qualitative data and measurements

- Statistical Algorithms and / or simplified physical methods:

- Weather forecast model. [3]

According [4] the prediction of the weather conditions may be accomplished by numerical climate models called NWP ("Numerical Weather Predicction"), which as already mentioned, this is the model that will be used in this present study.

Within the numerical model NWP two forecasting techniques, RAMS and WRF will be used, from which are obtained from the different evaluation indices and compared with other comparative graphs and tables mediants ones.

\subsection{Numerical forescasting models.}

According [4] a numerical prediction model attempts to establish the relationship between the historical values and a series of variables that may be related to this value, as the NWP forecast of the meteorological variables surrounding areas. There are many techniques of numerical models to predict, but we we'll pay attention on two: RAMS, and WRF, because they are provided by the Ceará Foundation of Meteorology and Water Management (FUNCEME), daily predictions.

\subsection{Indexes of performance evaluation of forecasts}

In this section we will define a series of techniques to be considered when evaluating the errors committed by the forecasts. The main indexes of the performance evaluation of the predictions are shown in Table 1:

\section{Theoretical foundation}

According to [5], one of the sources of data available for the state of Ceará - Brazil are the predictions from numerical models, where the FUNCEME due to the large volume of information, were saved only images of the predictions made. Worked these images you can retrieve a value of wind speed forecast for a specific city. The focus of interest are the images of speed and wind direction at 10 meters height equivalent to the height of the meteorological towers FUNCEME. Images are transferred in the form of compressed files according to the daily simulations.
Table 1 - Indices of performance evaluation

\begin{tabular}{|c|c|c|}
\hline Evaluation Index & Formula & \\
\hline MSE (mean squared error) & $M S E_{k}=\overline{e_{k}}=\frac{1}{N_{T}} \sum_{t=1}^{N}\left(e_{t+k \mid t}\right)^{2}$ & (1) \\
\hline MAE (mean absolute error) & $M A E=\frac{1}{n} \sum_{i=1}^{n}\left|f_{i}-y_{i}\right|=\frac{1}{n} \sum_{i=1}^{n}\left|e_{i}\right|$ & (2) \\
\hline $\begin{array}{l}\text { RMSE (root mean squared } \\
\text { error) }\end{array}$ & $R M S E_{k}=\sqrt{R M S E_{k}}=\sqrt{\frac{1}{N_{T}} \sum_{t=1}^{N}\left(e_{t+k \mid t}\right)^{2}}$ & (3) \\
\hline $\begin{array}{l}\text { MARE (mean absolute } \\
\text { relative error) }\end{array}$ & MARE $=\frac{1}{n} \sum_{i=1}^{n} \frac{\left|w_{o}-w_{p}\right|}{w_{o}}$ & (4) \\
\hline $\begin{array}{l}\text { MSRE ( } \text { mean squared } \\
\text { relative error) }\end{array}$ & $M S R E=\frac{1}{n} \sum_{1}^{n}\left(\frac{Q \hat{\imath}-Q i}{Q i}\right)^{2}$ & (5) \\
\hline $\begin{array}{l}\text { RMSRE ( root mean squared } \\
\text { relative error) }\end{array}$ & $R M S R E=\sqrt{\frac{1}{n} \sum_{1}^{n}\left(\frac{Q \hat{\imath}-Q i}{Q i}\right)^{2}}$ & (6) \\
\hline $\begin{array}{l}\text { MAPE (mean absolute } \\
\text { percentage error) }\end{array}$ & $M A P E=\frac{100 \%}{n} \sum_{t=1}^{n}\left|\frac{A_{t}-F_{t}}{A_{t}}\right|$ & (7) \\
\hline $\begin{array}{l}\text { MSPE ( mean squared } \\
\text { percentage error) }\end{array}$ & $M S P E=\frac{\sum_{j=1}^{V}\left(\frac{E_{j}}{A_{j}}\right)^{2}}{V}$ & (8) \\
\hline $\begin{array}{l}\text { RMSPE ( root mean squared } \\
\text { percentage error) }\end{array}$ & $R M S P E=\sqrt{\frac{\sum_{j=1}^{V}\left(\frac{E_{j}}{A_{j}}\right)^{2}}{V}}$ & (9) \\
\hline
\end{tabular}

Initially a code image processing speed of the wind, which decompresses these files sequentially preparing a directory with images related to the speed and wind direction at $10 \mathrm{~m}$ was generated .

Images are maps with colors relating to greatness in the study and follow a pattern, there are references in this map latitude and longitude axes of the image, so it was possible to relate a coordinated equivalent pixel, as shown in Figure 1, points A, B, C and D are the pixel coordinates of the vertices of the grid simulation, zero latitude is equivalent to the pixel .

Figure 1 Identification of the pixels compared with Latitude and Longitude

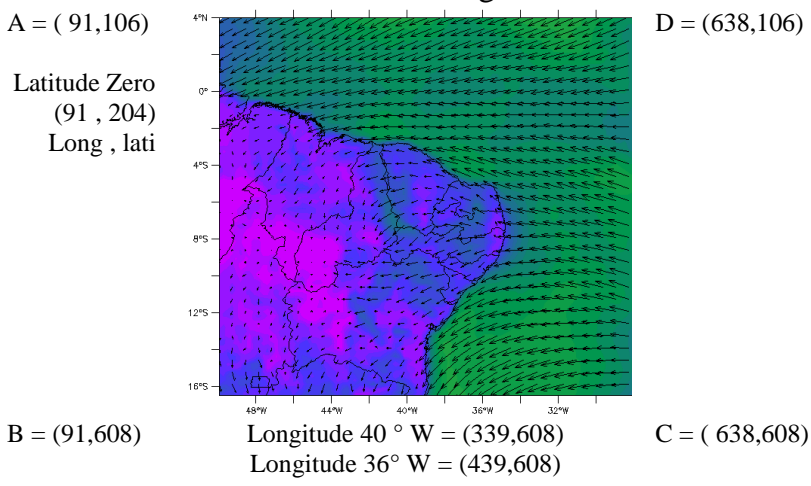

In section 6 an analysis of different articles by various authors will be held and conclude that the three most commonly used indices are: "ASM", "MAE" and "RMSE". That is why this work will be used to review these three indexes

\section{Methodology Used}

Steps of the methodology:

1) Data processing of numerical models: RAMS and WRF.

2) Creation of accumulators, which will contain the wind speeds predicted and actual, for all days of the year, for each numerical model. 
3) Calculation of the index of performance evaluation.

\subsection{Processed Data}

Each of the five numerical model has two rounds of daily forecasts for each of the variables. Considering the first round at zero hour and the second one at 12 hours, each of these rounds makes 14 predictions. The first round gives forecasts 3 to 81 hours ahead, with a step of 6 hours. The second round gives forecasts 15 to 93 hours ahead, also with a step of 6 hours (Table 2).

Table 2. Scales for each round of prediction.

\begin{tabular}{|c|c|c|c|}
\hline & & \multicolumn{2}{|c|}{ DAY 5 } \\
\hline Date & Hour & forecast 0h & Forecast 12h \\
\hline $05 / 02 / 2009$ & 3 & 3 & \\
\hline $05 / 02 / 2009$ & 9 & 9 & \\
\hline $05 / 02 / 2009$ & 15 & 15 & \\
\hline $05 / 02 / 2009$ & 21 & 21 & \\
\hline $06 / 02 / 2009$ & 3 & 27 & 15 \\
\hline $06 / 02 / 2009$ & 9 & 33 & 21 \\
\hline $06 / 02 / 2009$ & 15 & 39 & 27 \\
\hline $06 / 02 / 2009$ & 21 & 45 & 33 \\
\hline $07 / 02 / 2009$ & 3 & 51 & 39 \\
\hline $07 / 02 / 2009$ & 9 & 57 & 45 \\
\hline $07 / 02 / 2009$ & 15 & 63 & 51 \\
\hline $07 / 02 / 2009$ & 21 & 69 & 57 \\
\hline $08 / 02 / 2009$ & 3 & 75 & 63 \\
\hline $08 / 02 / 2009$ & 9 & 81 & 69 \\
\hline $08 / 02 / 2009$ & 15 & & 75 \\
\hline $08 / 02 / 2009$ & 21 & & 81 \\
\hline $09 / 02 / 2009$ & 3 & & 87 \\
\hline $09 / 02 / 2009$ & 9 & & 93 \\
\hline
\end{tabular}

In this way, after five days of predictions, each parameterization has accumulated predictions for a same moment (Table 3).

Table 3. Wind speed forecasts accumulated for a same moment.

\begin{tabular}{|c|c|c|c|c|c|c|c|c|c|c|}
\hline & & \multicolumn{10}{|c|}{ Days } \\
\hline & & \multicolumn{2}{|c|}{5} & \multicolumn{2}{|c|}{6} & \multicolumn{2}{|c|}{7} & \multicolumn{2}{|c|}{8} & 9 \\
\hline date & hour & Oh & $12 \mathrm{~h}$ & Oh & $12 \mathrm{~h}$ & 0h & $12 \mathrm{~h}$ & 0h & $12 \mathrm{~h}$ & 0h \\
\hline $08 / 12 / 09$ & 15 & & 6,7 & 6,7 & 6,2 & 6,2 & 6,2 & 6,2 & & \\
\hline $08 / 12 / 09$ & 21 & & 6 & 5,4 & 5,5 & 5,2 & 4,7 & 4,7 & & \\
\hline $09 / 12 / 09$ & 3 & & 4,2 & 4,2 & 3,7 & 3,7 & 3,7 & 3,7 & 4,2 & 3,2 \\
\hline $09 / 12 / 09$ & 9 & & 6,2 & 6,2 & 5,7 & 5,2 & 5,2 & 5,2 & 5,7 & 5,2 \\
\hline $09 / 12 / 09$ & 15 & & & & 5,7 & 6,2 & 5,7 & 6,2 & 6,2 & 6,2 \\
\hline $09 / 12 / 09$ & 21 & & & & 68 & 5,2 & 5,7 & 5,2 & 4,7 & 4,7 \\
\hline
\end{tabular}

\subsection{Mounting of Accumulators}

Accumulators were created to group the predictions of each scale prediction. We then have 28 accumulators: acum300h, acum $1512 \mathrm{~h}$, acum $2700 \mathrm{~h}$, acum $3912 \mathrm{~h}$, acum5100h, acum6312h, acum7500h, acum8712h, acum900h, acum $2112 \mathrm{~h}$, acum $3300 \mathrm{~h}$, acum $4512 \mathrm{~h}$, acum6912h, acum8100h, acum9312h, acum $1500 \mathrm{~h}$, acum2712h, acum3900h, acum5112h, acum6300h, acum7512h, acum2100h, acum2100h, acum $3312 \mathrm{~h}$, acum4500h, acum5712h, acum6900h, acum8112h. Each accumulator will save the set of all predictions to the same scale prediction, later to be compared with the values of real measurements. This procedure will evaluate how each scale predicted by the numerical model is closer to the actual value measured by an anemometer.

\subsection{Calculation of indices for evaluating performance}

We will work in the range of one year, beginning in June 2010 and ending in May 2011, we will divide the year into four quarters: June to August (quarter 1), September to November (quarter 2), December to February (quarter 3), and from March to May (quarter 4). The first two quarters are considered dry season, and the last two quarters of the rainy season. For each quarter we have 45 samples of forecasts of wind speed and their actual values of the velocities for each numerical model. With these predicted values and the actual index of MAPE error was calculated. So it was evaluated the numerical model that will best approached reality for each quarter.

\section{Index Performance Evaluation of Numerical Model Forecasts}

In this section a survey of the use of indexes of the performance evaluation was conducted to identify the most common indices in the literature, this study is presented in Table 4.

Table 4 - Survey of the use of indices for evaluating performance.

\begin{tabular}{|c|c|c|c|}
\hline & 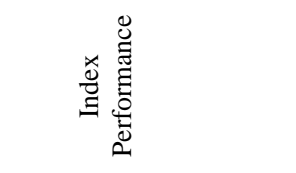 & 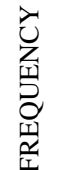 & 竞 \\
\hline 1 & $\begin{array}{c}\text { MSE (mean squared } \\
\text { error) }\end{array}$ & 5 & $\begin{array}{c}11],[14],[33], \\
{[38],[40]}\end{array}$ \\
\hline 2 & $\begin{array}{l}\text { root-mean-square } \\
\text { deviation (RMSD) } \\
\text { or } \\
\text { root-mean-square } \\
\text { error (RMSE) }\end{array}$ & 19 & $\begin{array}{l}{[6],[7],[8],[10],} \\
{[11],[12],[13],} \\
{[18],[19],[20],} \\
{[21],[22],[24],} \\
{[26],[29],[36],} \\
{[41],[42],[50]}\end{array}$ \\
\hline 3 & $\begin{array}{c}\text { MAPE ( mean } \\
\text { absolute percentage } \\
\text { error) }\end{array}$ & 13 & $\begin{array}{c}{[5],[6],[13],[14],} \\
{[23],[25],[38],} \\
{[40],[44],[46],} \\
{[47],[48],[49]}\end{array}$ \\
\hline 7 & MAD & 4 & $\begin{array}{c}{[12],[37],[38],} \\
{[43]}\end{array}$ \\
\hline 8 & Residual Variance & 2 & [34], [35] \\
\hline 10 & $\begin{array}{c}\% \text { prediction } \\
\text { accuracy }\end{array}$ & 2 & {$[39],[45]$} \\
\hline 16 & NRMSE & 3 & {$[18],[30],[31]$} \\
\hline 17 & NMAE & 3 & [9], [21], [32] \\
\hline 18 & MAE & 11 & $\begin{array}{l}{[7],[11],[14],[15],} \\
{[16],[17],[21,[25]}\end{array}$ \\
\hline
\end{tabular}

This analysis found a wide variety of indices used and the most common were RMSE, MAE and MAPE. 


\section{Comparative Results}

In this section are graphically presented the evaluation results for each quarter, identifying the behavior of each numerical model in each quarter. In this study, the forecasts were evaluated using the MAPE index. where, the closer to zero the index, the more the prediction approached the actual value. Were compared, the MAPE of 45 samples of each expected range, 3-93 hours ahead, for RAMS and WRF models for two daily rounds, the round noon $(12 \mathrm{~h})$, and round midnight $(00 \mathrm{~h})$ :

For the quarter June to August of 2010 we have:

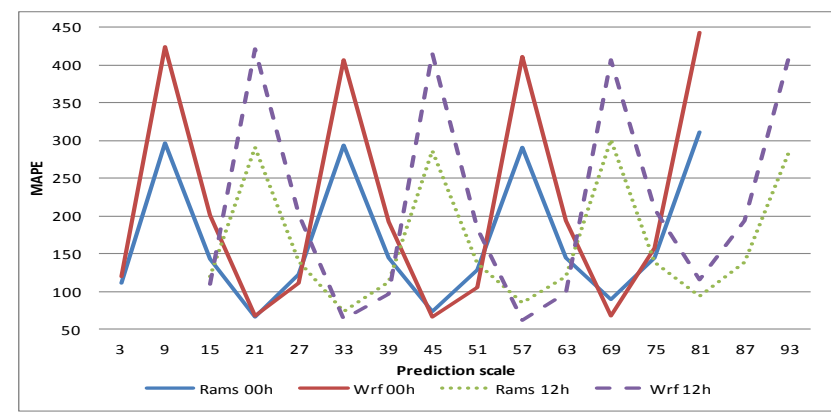

Fig.2 Mape Fig.45 samples Quarter 1 rounds 00h and 12h

We observe an oscillation between the performances of simulations midnight and noon. We also observed a slightly better performance of the RAMS model.

For the quarter September to November of 2010 we have:

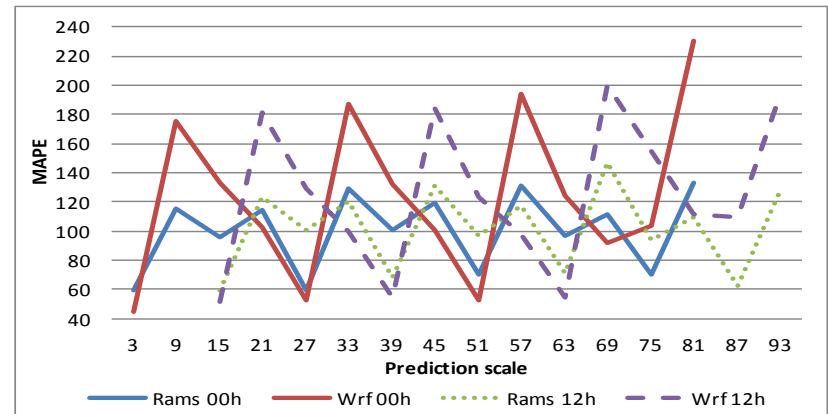

Fig. 3 Mape 45 samples Quarter 2 rounds $00 \mathrm{~h}$ and $12 \mathrm{~h}$

For the second quarter to the first analyzed a similar behavior was observed. For the quarter December to February of 2010/2011 we have:

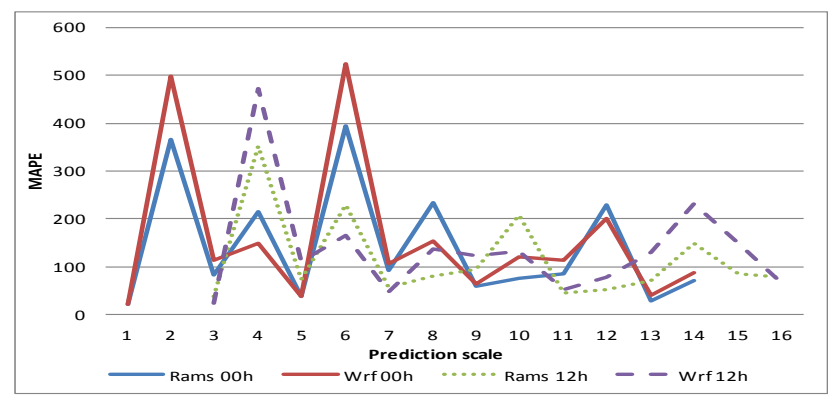

Fig. 4 Mape 45 samples Quarter 3 rounds $00 \mathrm{~h}$ and $12 \mathrm{~h}$

For the third quarter analyzed the previous behavior was also observed, but the predictions tended to a greater success in the scales predicted from seven hours ahead.
For the quarter March to May of 2010 we have:

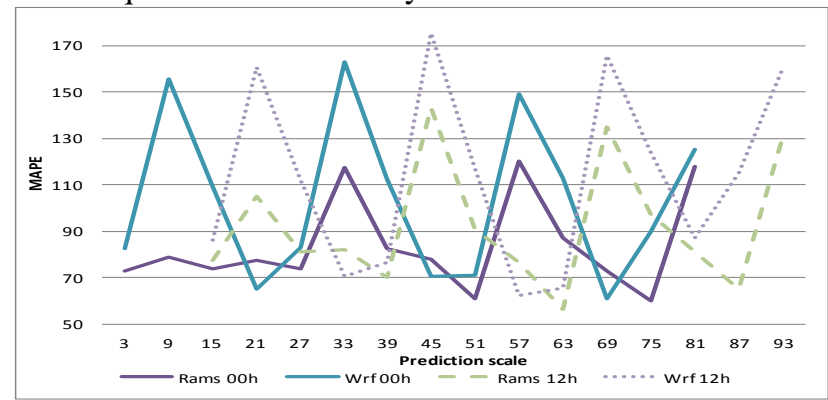

Fig. 5 Mape 45 samples Quarter 4 rounds $00 \mathrm{~h}$ and $12 \mathrm{~h}$

In the fourth quarter the same behavior was observed oscillation between performance and better performance of RAMS model.

\section{Conclusion}

In the present study we determined the wide variety of performance indices used, standing out as the three most widely used indexes: "MAE", "MAPE" and "RMSE" or (RMSD). We can also say that in this study the dry season and in the rainy numerical model that best approached to reality was: "RAMS". Also notable was a cyclical and complementary behavior between the results of the predictions made at $00 \mathrm{~h}$ and $12 \mathrm{~h}$, usually when one is bad the other is better. The present study is an analysis tool for users and developers of numerical models, it demonstrates their behavior in different seasons. These results serve as indicative of adjustments in parameterization of models, trying to adapt them to regional conditions, specifically wind variable.

\section{References}

[1] (http://ingenieriaenlared.wordpress.com/2007/11/28/seprevee-un-crecimiento-anual-del-30-de-la-energia-eolicamundial-instalada/)

[2] CHAMADA $\mathrm{N}^{\circ}$ 017/2013 PROJETO ESTRATÉGICO: "DESENVOLVIMENTO DE TECNOLOGIA NACIONAL DE GERAÇÃO EÓLICA".ANEEL. Brasília, DF. Abril de 2013. available in: < http://www.aneel.gov.br/arquivos/PDF/PD\%20Estrat\%C3\% A9gico\%20017-2013.pdf>

[3] Mapa y Predicción EÓLICA Evaluación de los recursos y potenciales de EERR. Available in: <(http://www.agenergia.org/files/resourcesmodule/@rand om499e8e8d0ea7a/1235568147_presentacion_eramac_ma pa_y_prediccion_eolicalTC.pdf>

[4] DE BORJA GARCIA BARROS, Francisco. Estrategias de programación diaria y operación horaria en el mercado de la electricidad de un parque eólico dotado de un sistema acumulador de energía. Sevilla. 2006.

[5]SILVA, F.D.L.; CARVALHO, P. C. M.; A. R. Paula; A. P. S Braga. 3 to 69 hours wind speed forecasting using artificial neural networks for the Brazilian Northeast region. Bilbao , Spain 2013.

[6]CASTRO SOUZA, Reinaldo. Previsão da geração eólica. Pontifica Universidade Católica do Rio de Janeiro, 2010.

[7]JUBAN, Jeremie; FUGON, Lionel and KARINIOTAKIS George. Probabilistic short-term wind power forecasting based on kernel density estimators. Milan, Italy 2007.

[8]PALOMARES-SALAS, J.C.; DE LA ROSA, J.J.; RAMIRO, J.G.; MELGAR,J. ; AGÜERA,A; and MORENO,A. 
Comparison of Models for Wind Speed Forecasting. Universidad Politecnica Superior. Algeciras,Cadiz, 2007.

[9]MIRANDA,Vladimiro; BESSA,Ricardo; GAMA,João; CONZELMAN, Guenter; BOTTERUD, Audun. New Concepts in Wind Power Forecasting Models. University of Porto,Portugal 2008

[10]TRANCOSO, Ana Rosa; DELGADO DOMINGOS, J.; PESTANA, Rui. Previsibilidade da Energia Eólica. Instituto Superior Técnico, Secção de Ambiente e Energia. Spain 2006.

[11]KEMALETTIN TERZIN, Umit ; ONAT, Nevzat and ATIS, Selçuk. New Hybrid Method Proposal for Wind Speed Prediction: a Case Study of Lüleburgaz. Technical Education Faculty, University of Marmara 2011.

[12]LAZIC, Lazar; PEJANOVIC, Goran; ZIVKOVIC, Momcilo. Wind forecasts for wind power generation using the Eta model. South Environment and Weather Agency, Belgrade, Serbia 2010.

[13]GONG, Li; JING, Shi. On comparing three artificial neural networks for wind speed forecasting. Department of Industrial and Manufacturing Engineering, North Dakota State University 2010.

[14]LIU, Hui ; TIAN, Hong-Qin; CHEN, Chao ; LI, Yan-fe. A hybrid statistical method to predict wind speed and wind power. Australia. 2010

[15]KUSIAK, Andrew; ZHENG, Haiyang; SONG, Zhe. Models for monitoring wind farm power. Department of Mechanical and Industrial Engineering, University of Iowa, Iowa city 2009.

[16] SALCEDO-SANZA, Sancho; PEREZ BELLIDO, Angel M. ; ORTIZ-GARCIA, Emilio G.; PORTILLA-FIGUERAS, Antonio; PRIETO, Luis; PAREDES, Daniel . Hybridizing the fifth generation mesoscale model with artificial neural networks for short-term wind speed prediction. Madrid, Espanha. 2009.

[17]KUSIAK, Andrew; ZHENG, Haiyang; and SONG, Zhe. Wind Farm Power Prediction: A Data-Mining Approach. Department of Mechanical and Industrial Engineering, University of Iowa, Iowa City, USA 2008

[18]LANGE, Bernhard. Experiences from the development of wind power forecasts for six european TSO. Madrid 2008.

[19]VLASOVA, Julija; KOTWA, Ewelina; AALBORG NIELSEN, Henrik ; MADSEN, Henrik. Spatio-temporal modelling of short-term wind power prediction errors. Informatics and Mathematical Modelling Technical University of Denmark 2007.

[20]VON BREMEN, Lueder; SALECK, Nadja; and HEINEMANN, Detlev. Enhanced regional forecasting considering single wind farm distribution for upscaling. Oldenburg 2007.

[21]GIEBEL,Gregor ; SORENSES, Paul; HOLTTINEN RISO, Hannele. Forecast error ofaggregated wind power. Alemanha 2007.

[22]VON BREMEN, Lueder. Combination of Deterministic and Probabilistic Meteorological Models to enhance Wind Farm Power Forecasts. For Wind-Centre for Wind Energy Research, University Oldenburg, Germany 2006.

[23]HAYATI, Mohsen and SHIRVANY, Yazdan. Artificial Neural Network Approach for Short Term Load Forecasting for Illam Region. 2007.

[24] ERNST, Bernhard; ROHRIG, Kurt; JURSA, René. ONLINE-MONITORING AND PREDICTION OF WIND POWER IN GERMAN TRANSMISSION SYSTEM OPERATION CENTRES. Institut für Solare Energieversorgungstechnik e. V. Königstor 59, D Kassel, Germany. 2004.

[25]TEXEIRA JUNIOR, Luiz Albino; MOREIRA PESSANHA, José Francisco; CASTRO SOUZA. Análise wavelet e redes neurais artificiais na previsão da velocidade de vento. Rio de janeiro 2011.
[26]MILLIGAN, Michael; SCHWARTZ, Marc and YIH-HUEI, Wan. Statistical wind power forecasting for u.s. wind farms. National Renewable Energy Laboratory, Golden, Colorado. 2003.

[27] KHANH, T.Tran. Development and Testing of a Wind Energy Forecasting System. Texas,2004.

[28]KANDILL, M.S, S.M., El-Debeiky; N.E, Hasanien Overview and comparison of long-term forecasting techniques for a fast developing utility: part I. Egypt 2000.

[29]ZACK, John. Overview of wind energy generation forecasting. New York 2003.

[30]GONZALEZ, Gerardo. Wind power prediction in the Spanish system operation (peninsula and islands) Sipreólico. Madrid, 2008.

[31]JUBAN, Jeremie; FUGON, Lionel and KARINIOTAKIS George. Probabilistic short-term wind power forecasting based on kernel density estimators. Milan, Italy 2007.

[32]LANG S.; MÖHRLEN C.; JORGENSEN J.; Ó GALLACHOIRL B.; MCKEOGH E. Application of a MultiScheme Ensemble Prediction System for wind power forecasting in Ireland and comparison with validation results from Denmark and Germany. Sustainable Energy Research Group, University College Cork, Ireland, 2005.

[33]CHAKRABORTY, K.; MEHROTRA, K.; MOHAN, C.K.; RANKA, S. Forecasting the behavior of multivariate time series using University. Syracuse 1992.

[34]COTTRELL, M.; GIRAD, B.; GIRAD,Y.; MANGEAS, M.; MULLER, C. Neural modeling for time series: a statistical stepwise method for weight elimination. IEEE Transactions on Neural Networks. Paris 1995.

[35]DE GROOT, C.; WURTZ, D. Analysis of univariate time series with connectionist nets: a case study of two classical examples. Neurocomputing. Switzerland, 1991.

[36]GINZBURG, I.; HORN, D. Combined neural networks for time series analysis. Advances in Neural Information Processing Systems. USA, 1994.

[37]GORR, W.L.; NAGIN, D.; SZCYPULA, J. Comparative study of artificial neural network and statistical models for predicting student grade point averages. International Journal of Forecasting .Pittsburgh, USA 1994.

[38]KANG, S. An Investigation of the Use of Feedforward Neural Networks for Forecasting. USA, 1991.

[39] GRUDNITSKI, G.; OSBURN, L. Forecasting S and P and gold futures prices: An application of neural networks. The Journal. San Diego, USA 1993.

[40]KOHZADI，N.; BOYD， M.S.; KERMANSHASHI，B.; KAASTRA, I. A comparison of artificial neural network and time series models for forecasting commodity prices. Neurocomputing. USA 1996.

[41]KRYZANOWSKI, L.; GALLER, M.; WRIGHT, D.W. Using artificial neural networks to pick stocks. Financial Analysts Journal. Charlottesville 1993.

[42]LACHTERMACHER, G.; FULLER, J.D. Backpropagation in time- series forecasting. Journal of Forecasting.1995.

[43]NAM, K.; SCHAEFER, T. Forecasting international airline passenger traffic using neural networks. Logistics and Transportation. Vancouver 1995.

[44]NELSON, M.; HILL, T.; REMUS, B.; O`CONNOR, M. Can neural networks be applied to time series forecasting and learn seasonal patterns: An empirical investigation. In: Proceedings of the Twenty seventh Annual Hawaii International Conference Reynolds, on System Sciences. 1994.

[45]SCHONEBURG, E. Stock price prediction using neural networks: A project report. Neurocomputing. Berlin 1990.

[46]SHARDA, R.; PATIL, R.B. 1990. Neural networks as forecasting experts: An empirical test. In: Proceedings of the International Joint Conference on Neural Networks.Washington 1990. 
[47]SRINIVASAN, D.; LIEW, A.C.; CHANG, C.S. A neural network short-term load forecaster. Electric Power Systems Research. 1994.

[48]TANG, Z.; FISHWICK, P.A. Feedforward neural nets as models for time series forecasting. ORSA Journal on Computing. 1993.

[49]VISHWAKARMA, K.P. A neural network to predict multiple economic time series. In: Proceedings of the IEEE International. Conference on Neural Networks. 1994.

[50]ZHANG, X. Time series analysis and prediction by neural networks. Optimization Methods and Software. 1994. 